\title{
Pola Manajemen Fudraising Wakaf Uang (Studi Kasus pada Yatim Mandiri Cabang Kudus)
}

\author{
Eni Pratiwi, Jaenal Arifin, M. Nurul Qomar \\ Institut Agama Islam Negeri (IAIN) Kudus \\ mnqomar@iainkudus.ac.id
}

\begin{abstract}
This study is concerned with zakat management organizations, infaq, alms and waqf, where there are fundraising activities, especially waqf. Fundraising is an activity in order to raise funds and other resources from the community, both individuals, organizations and legal entities. Fundraising requires good management. Management functions ranging from planning, organizing, actuating and controlling are implemented so that waqf fundraising runs well. With the existence of the Yatim Mandiri Kudus branch which is active in fundraising, it is hoped that it can maximize the potential of waqf in Kudus so that it can help people in need in Kudus, especially the dhu'afa orphans. The problem in this research is how to manage waqf fundraising at the Yatim Mandiri Kudus branch. This type of research is a descriptive field research with a qualitative approach. The data collection techniques use literature review, observation and in-depth interviews with the manager of the Yatim Mandiri branch of Kudus as primary and secondary data. The results of this study are the management of waqf fundraising at the Yatim Institute. Mandiri Kudus, it can be concluded that, Yatim Mandiri Kudus Planning is doing well, by making a program arrangement to be delivered, and by applying two fundraising methods, namely direct and indirect Fundraising. Organizing and directing have been carried out well, determining the area for taking, recruiting and mentoring new fundraisers, led directly by the head of the Yatim Mandiri Kudus branch. And also well-managed supervision, starting from measuring the performance of fundraiser employees and ongoing achievements. Meanwhile, the Kudus branch of the LAZNAS Yatim Mandiri institution itself has programs related to waqf and other programs, such as zakat, shadaqah, donation to support the institution.
\end{abstract}

Keyword : Waqf, Fundraising, Manajement Yatim Mandiri

\section{Latar Belakang}

Salah satu lembaga ekonomi Islam yang sangat berperan dalam pemberdayaan ekonomi umat adalah wakaf. Dalam sejarah, wakaf telah berperan dalam pengembangan sosial, ekonomi, dan budaya masyarakat. 
Hal-hal yang menonjol dari lembaga wakaf adalah peranan dalam membiayai berbagai kegiatanagama Islam, pendidikan, kesehatan. Kondisi inilah kemudian memerlukan adanya reformasi didalam manajemen dan administrasi harta wakaf. Wakaf uang diharapkan dapat menjadi sasaran bagi rekontroksi sosial dan pembangunan, dimana mayoritas penduduk dapat ikut berpartisipasi. Untuk mewujudkan partisipasi tersebut, berbagai upaya pengenalan tentang arti penting wakaf termasuk wakaf tunai sebagai saran mentransfer tabungan si kaya pada para usahawan (entrepreneurs) dan anggota masyarakat dalam mendanai berbagai kegiatan. Dan dalam perwakafan tak luput dari namanya penggalangan dana (fundraising) guna berjalannya roda lembaga itu tersendiri. ${ }^{1}$

Fundraising (penggalangan dana) tidak hanya identik dengan menghimpun dana semata. Ruang lingkupnya begitu luas dan mendalam, berpengaruh besar bagi eksistensi dan pertumbuhan sebuah lembaga. ${ }^{2}$ Oleh karenanya, tidak begitu mudah untuk memahami ruang lingkup fundraising. Adapun fundraising pada lembaga non profit (nirlaba) seperti Laznas salah satunya adalah melalui ziswaf dari masyarakat. ${ }^{3}$ Ziswaf (Zakat, Shodaqoh, Infaq, dan Wakaf) sendiri ialah menjadi bagian dari instrumental dalam mengentas kemiskinan masyarakat. Karena, dari ziswaf salah satunya organisasi non profit bisa mencapai tujuan-tujuan mereka. Di kudus, sudah ada beberapa lembaga yang mencoba mengelola wakaf uang, seperti : Yatim Mandiri, Lazismu, Lazisnu, BMH, IZI. Salah satu yang menjadi penelitian kali ini adalah Laznas Yatim Mandiri cabang Kudus, didalam lembaga tersebut memiliki banyak program seperti zakat, infak, sedekah, serta wakaf. Dari beberapa program tersebut, wakaf uang menjadi penelitian kami,

Dalam penghimpunan dana wakaf yang dilakukan Yatim Mandiri dalam bentuk fundraising, yang meliputi metode langsung (direct fundraising) dan metode tidak lansung (indirect fundraising). Penelitian ini akan mengkaji bagaimana manajemen fundraising wakaf uang di Yatim Mandiri cabang Kudus?.

\section{Landasan Teori}

Istilah manajemen berasal dar kata to manage berarti control. Manajemen dapat dikatakan suatu proses yang meliputi perencanaan,

\footnotetext{
${ }^{1}$ K. Lubis Suhrawandi, Wakaf dan Pemberdayaan Umat. Jakarta: Sinar Grafika, 2010, 21.

${ }^{2}$ Hendi Suhendi (2018), “Optimalisasi Aset Wakaf sebagai Sumber Dana Pesantren Melalui Pelembagaan Wakaf", Tahkim, Jurnal Peradaban dan Hukum Islam, 1(1), 1-20.

3 M. Guffar Harahap (2019), "Strategi Fundrasing Wakaf di Badaan Wakaf Pondok Pesantren Mawaridussalam", AT-Tawassuth, IV(2), 301-322.
} 
pengorganisasian, pengarahan, dan pengawasan yang dilakukan para manajer dalam sebuah organisasi agar tujuan yang telah diinginkan dapat terwujud. ${ }^{4}$

Menurut Kathryn M. Bartol dan David C. Martin sebagaimana dikutip Khalifah Muhammad Ali, manajemen adalah suatu proses yang terdiri dari planning, organizing, leading, dan controlling yang dilakukan untuk mencapai tujuan yang ditetapkan dengan melibatkan pengetahuan bagaimana melaksanakan fungsi-fungsi utama manajemen. Semua unsur tersebut agalah bagian proses yang terikiat satu paket dalam satu pola yang bersifat hierarkis. ${ }^{5}$

Dalam perwakafan, pengelola wakaf sangat membutuhkan manajemen dalam menjalankan tugasnya. ${ }^{6}$ Manajemen ini digunakan untuk mengatur kegiatan pengelolaan harta wakaf, menghimpun wakaf uang, dan menjaga hubungan baik antara nadzir, wakif, dan masyarakat. ${ }^{7}$

Wakaf adalah menahan harta baik secara abadi maupun sementara, untuk dimanfaatkan langsung atau tidak langsung, dan diambil manfaat hasilnya secara berulang-ulang di jalan kebaikan baik umum atau khusus. $^{8}$ Demikian juga, wakaf merupakan sesuatu yang dapat memberikan manfaat secara berulang-ulang untuk tujuan tertentu selama beberapa kurun waktu. ${ }^{9}$

Fundraising adalah suatu kegiatan dalam rangka menghimpun dana dan sumber daya lainnya dari masyarakat baik individu, organisasi maupun badan hukum, yang akan digunakan untuk membiayai program dan kegiatan operasional lembaga yang pada akhirnya untuk mencapai misi dan tujuan lembaga tersebut. Fundraising merupakan suatu kewajiban bagi lembaga dalam menjalankan programnya. ${ }^{10}$

Penelitian dari Miftahul Huda (2015) "Model Manajemen Fundraising" meneliti tentang wakaf melalui sumber-sumber, produktifitas asset wakaf, dan wakaf pada Yayasan Dana Sosial al-Falah

4 Pandji Anaroga, Manajemen Bisnis. Jakarta: Rineka Cipta, 2014, 109.

5 Khalifah Muhammad Ali; Meida Yudiani; Sri Mulatsih (2018), "Apek-Aspek Prioritas Manajemen Wakaf di Indonesia", al-Falah: Journal of Islamic Economics, 3(1), 3-4.

6 Mohammad Noviani Ardi (2020), “Waqf fundraising Strategy for Islamic Boarding's Independence", Ijtihad, 20(1), 1-20.

${ }^{7}$ Rozalinda, Manajemen Wakaf Produktif. Jakarta: Rajawali Press, 2016, 72.

8 Rahmi Septiyani; Ahmad Djalaluddin; Misbahul Munir (2018), "Telaah Strategi Fundraising Wakaf Tunai Mewujudkan Pemberdayaan Masyarakat (Studi kasus Kawasan Baitul Maal Hidayatullah Perwakilan Jawa Timur)", Islamic Economics Quotient, 1(2), 6-19.

${ }^{9}$ Mmundzir Qahaf, Manajemen Wakaf Produktif. Jakarta: Khalifa, 2005, 52-53.

10 Muhsin Kalida (2004), “Fundraising dalam Studi Pengembangan Lembaga Kemasyarakatan, Jurnal Aplikasia, V(2), 151. 
(YDSF) Surabaya studi kasus menunjukkan bahwa yayasan menggunakan manajemen fundaraising wakaf dengan mengembangkan model resource fundraising seperti metode penggalangan sumber-sumber konvensional secara langsung maupun tidak langsung dan model grant fundraising seperti penguatan program pemberdayaan pada penyaluran wakaf. Sedangkan dalam pengembangan model aset fundraising dan wakaf YDSF belum dapat mengembangkannya sehingga YDSF termasuk nadzir wakaf yang masih dalam luster pengelolaan wakaf langsung.

Antara junal diatas dengan penelitian yang kami lakukan memiliki pembahasan yang sama-sama meneliti tentang fundraising wakaf tetapi juga sedikit memiliki perbedaan dalam penelitian ini lebih menitik beratkan model-model fundarising sedangkan penelitian kami lebih ke manajemen fundraising. ${ }^{11}$

Penelitian dari Ayub Dwijokangko (2018) dengan judul "Manajemen fundraising wakaf uang pada yatim mandiri tulungagung" berisi mengenai perencanaan dengan membuat maping area, maping tujuan, menyusun progam memperhitungkan waktu dan lain-lain diterapkan supaya fundraising wakaf uang berjalan dengan baik.

Persamaan dengan penelitian kami ialah sama-sama meneliti tentang manajemen fundraising wakaf pada lembaga yang sama yaitu Yatim Mandiri. Perbedaan penelitian ini adalah hanya lebih spesifik ke manajemen fundraisingnya saja, sedangkan dalam penelitian diatas lebih umum dalam mengenai manajemen fundraising, juga kendala-kedala dan solusinya dalam melakukan fundraising. ${ }^{12}$

\section{Metode Penelitian}

Jenis penelitian ini penelitian lapangan dengan menggunakan metode deskriptif dengan pendekatan kualitatif. ${ }^{13}$ Adapun teknik pengumpulan data dengan menggunakan kajian pustaka, observasi dan wawancara secara mendalam dengan manajer cabang Laznas Yatim Mandiri sebagai data primer dan sekunder, ${ }^{14}$ dari hasil penelitian menunjukkan bahwa pada tahapan manajemen fundraising wakaf peran penting seorang fundraiser nadzir serta wakif sangat di butuhkan di dalam pengembangan wakaf dengan melakukan pengamatan lingkungan sekitarnya terlebih dahulu untuk mempertahankan kepercayaan,

${ }^{11}$ Miftahul Huda (2015), “Model Manajemen Fundraising Wakaf”, Jurnal al-Ahkam, 13(1), 31-38.

${ }^{12}$ Ayup Dwijokangko (2018), "Manajemen Fundraising Wakaf Uang pada Yatim Mandiri”, Skripsi, IAIN Tulungagung, 148.

${ }^{13}$ Burhan Bungin, Penelitian Kualitatif. Jakarta: Kencana, 2008, 67.

${ }^{14}$ Sugiono, Memahami Penelitian Kualitatif. Bandung: Alfabeta, 2012, 1 
kekuatan dan mengambil peluang yang ada sehingga bisa meminimalisir kelemahan dan ancaman yang terjadi pada lingkungan sekitar sehingga bisa meningkatkan fundraising wakaf di lembaga tersebut.

\section{Hasil Penelitian}

\section{Sejarah Berdirinya Yatim Mandiri}

Yatim Mandiri yang berdiri pada tanggal 31 Maret 1994 menggunakan nama Yayasan Pembinaan dan Pengembangan Panti Asuhan Islam dan Anak Purna Asuh (YP3IS), lahir dari sebuah ide beberapa aktivitas yang peduli terhadap kondisi panti asuhan di Surabaya. Mereka adalah Drs. Hasan Sadzili, Syahid Haz, Bimo Wahyu Wardoyo, dan Nur Hidayat yang ingin menyatukan panti-panti asuhan yatim di Surabaya.

Setelah mengalami perjalanan panjang selama 14 tahun sejak berdirinya, berbagai catatan perjalanan telah terhimpun.Baik yang berkaitan dengan legalitas maupun operasional kesehariannya. Diantaranya; sesuai dengan undang-undang nomor 16 tahun 2000 tentang yayasan batas toleransi penyesuaiannya adalah tahun 2005, sehingga demi kepentingan publik yaysan harus melakukan pendaftaran ke Kemenkumham Pusat di Jakarta. Ternyata Depkumham menolak karena nama YP3IS terlalu panjang, kurang bisa memberikan fungsi branding yang markettable dalam pengembangan publikasi lembaga ke masyarakat.Maka dengan dorongan masyarakat dan hasil analisa internal, diubahlah menjadi nama yang sederhana dan syarat dengan makna, yaitu Yayasan Yatim Mandiri, dengan akronim Yatim Mandiri.Yatim Mandiri adalah Lembaga Amil Zakat Nasional yang telah memiliki legalitas melalui aspek legal formal. (www.yatimmandiri.org diakses pada tanggal 01-11-2018.)

Dalam perkembangannya Yatim Mandiri membuka beberapa cabang kantor,dan pada tahun 2013, Yatim Mandiri yang berpusat di Surabay membuka kantor cabang baru. Tepatnya di Jl. Ganesha 2 No. 4 Purwosari, Kudus, 59316, Telp.(0291) 2912735, 085640005495.

Struktur Organisasi Yatim Mandiri cabang Kudus

$\begin{array}{ll}\text { Ketua Cabang } & \text { : Ahmad Shohib Hasani } \\ \text { Staf Admin } & : \text { Zulaekha } \\ \text { Staf Program } & \text { : Fais Mujawidin } \\ \text { ZISCo YM Kudus } & \text { : Nila Farchati Firdaus } \\ & \text { Saiful Anwar } \\ & \text { Moh. Halimi } \\ & \text { Nihayatul Mila } \\ & \text { Rasnal Hi. Bisnu }\end{array}$




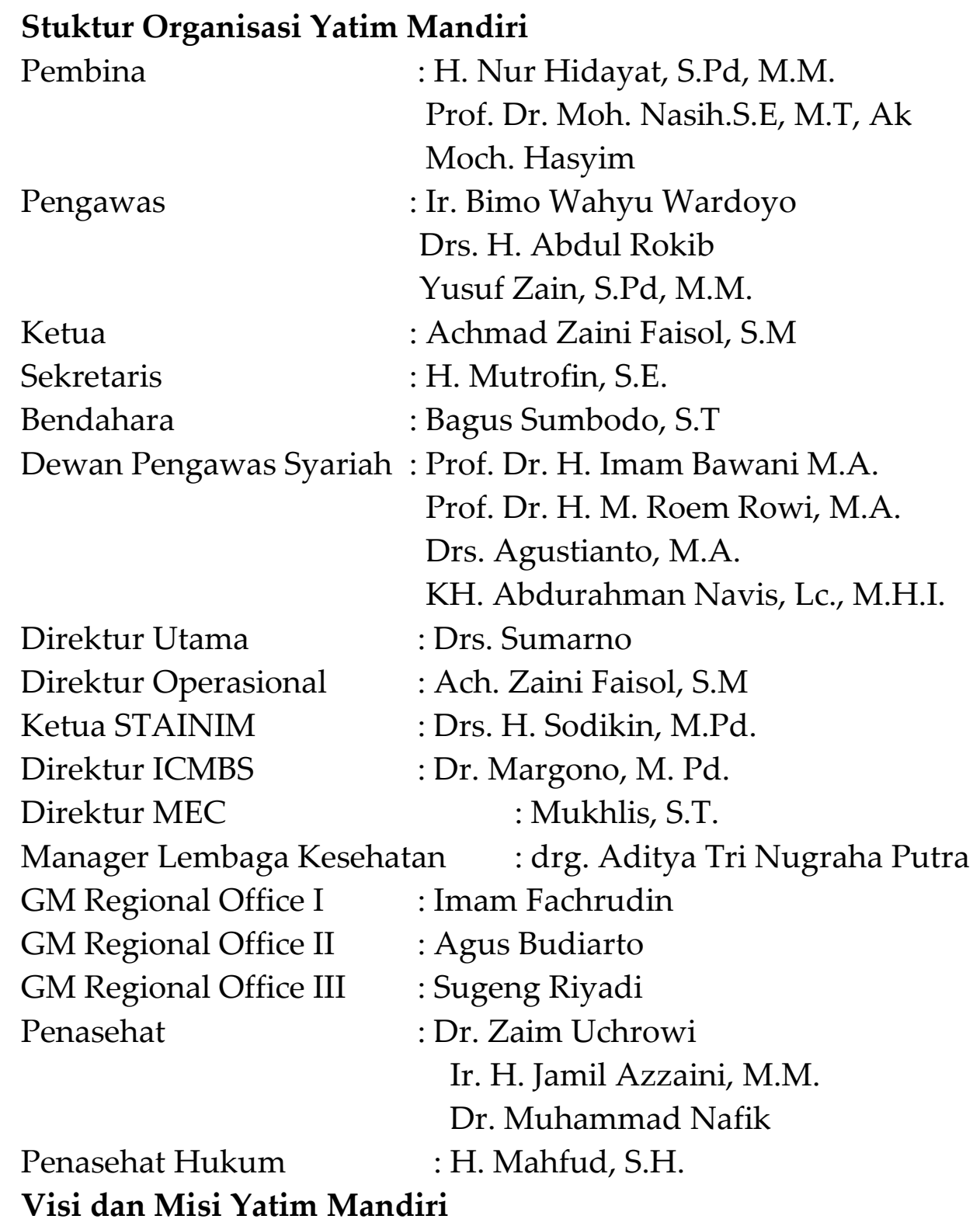

Sebagai sebuah organisasi Yatim Mandiri Kudus mempunyai visi dan misi.

a. Visi

1. Menjadi Lembaga terpercaya dalam membangun kemandirian yatim.

b. Misi

1. Membangun nilai-nilai kemandirian yatim dhuafa

2. Meningkatkan Partisipasi masyarakat dan dukungan sumberdaya untuk kemandirian yatim dan dhuafa.

3. Meningkatkan capacity building organisasi. (Majalah Yatim Mandiri, November 2018; 2)

\section{Program Kerja Yatim Mandiri}


Mengenai program kerja, Yatim Mandiri membaginya kedalam delapan program kerja besar yang nantinya direalisasikan dalam sub-sub program yang ada didalamnya. Berikut uraian sub-sub program yang dibentuk Yatim Mandiri untuk merealisasikan dana zakat, infak sedekah, dan wakaf.

1. Wakaf Produktif Pesantren Kemandirian

Semenjak berdiri, wakaf pesantren kemandirian yang selama ini dikelola masih sebatas menjalankan tugas pokok dan fungsi pendidikan serta pelatihan.Kemudian pada tahun 2018, pesantren kemandirian ditetapkan sebagai tempat implementasi program wakaf produktif oleh Badan Wakaf Mandiri Yayasan Yatim Mandiri. Berdasarkan UU No. 41 thn 2014 tentang wakaf dan Peraturan Pemerintah No. 42 thn 2016 tentang pelaksanaan wakaf, serta kewajiban sebagai nadzir yang diamanahkan untuk mengelola dana wakaf dan asset wakaf.

Maka Badan Wakaf Mandiri bersama Pesantren kemandirian menginisiasi sebuah program wakaf produktif, berupa ternak ayam kampung unggul.Harapan program wakaf produktif ternak ayam kampung ini, Pesantren Kemandirian mampu memproduksi DOC ayam Kampung unggul dan bertujuan untuk meningkatkan produksi ayam kampung. (Majalah Yatim Mandiri, November 2018; 32)

2. Program Pendidikan

a. BESTARI (Beasiswa Yatim Mandiri)

BESTARI merupakan bantuan biaya pendidikan untuk yatim dhuafa tingkat Sd, SMA se-Indonesia. Bantuan tersebut diberikan 2 kali dalam satu tahun. Dengan bantuan ini dapat memberikan semangat bagi anak-anak yatim dhuafa agar tidak putus sekolah.

b. Rumah Kemandirian (RK)

Rumah kemandirian adalah program pemberdayaan anak yatim dalam bidang pendidikan. Anak yatim dalam program RK diharapkan akan menjadi anak yang siap mental untul mandiri. Mereka akan dibekali dengan materi akidah, akhlak, al-Qur'an dan pelajaran umum. Potensi diri mereka juga akan terus dikembangkan selama pembinaan asrama. Disamping anak yang menjadi fokus binaan, para bunda yatim juga akan mendapat bimbingan dan pendampingan.

c. Sanggar Genius

Sanggar genius adalah program pembinaan yatim dhuafa dalam bidang akademik, khusunya matematika dan akhlak. 
Program ini berjalan 3 kali tiap pekannya dengan guru-guru pilihan. Melalui program ini anak-anak yatim dhu'afa dapat mengembangkan potensi dirinya.Hingga saat ini sudah tersebar banyak 320 sanggar di seluruh Indonesia.

\section{d.Duta Guru}

Duta guru adalah program pembinaan yatim dhu'afa dalam bidang al-qur'an dan diniyah yang di damping oleh ustadz ustadzah pilihan.Program ini berjalan 4 kali dalam satu pecan dan dominan di berbagai panti asuhan mitra dari yatim mandiri.

e. PLUS

Plus merupakan singkatan dari Pembinaan Lulus Ujian Sekolah. Sebuah program pembinaan untuk yatim dhu'afa yang akan menghadapi ujian nasional. Program tersebut memberukan bekal-bekal persiapan ujian sekolah agar anak yatim dhu'afa dapat lulus ujian sekolahnya dengan hasil memuaskan. Program ini dilaksanakan setiap menjelang ujian nasional.

f. ASA

ASA (Alat Sekolah) merupakan sebuah program bantuan untuk anak-anak yatim dhu'afa berupa alat-alat sekolah seperti buku tulis, tas sekolah,alat tulis dan yang lainnya. Program ini di gulirkan setiap tahunnya kepada 15000 anak saat kenaikan kelas. g.SUPERCAMP

Supercamp merupakan bentuk kegiatan untuk membentuk karakter kemandirian anak-anak yatim dhu'afa. Karakter kemandirian meliputi sikap-sikap dasr leadearship, percaya diri,manajemen diri dan sikap dasar muslim. Supercamp ini di ikuti oleh anak yatim dhu'afa tingkat SMP-SMA saat mereka liburan sekolah tiba.Setiap tahunnya program ini diikuti lebih dari 1000 anak.

\section{Program Kesehatan}

a. Layanan Kesehatan Keliling

Program layanan kesehatan keliling merupakan bentuk kegiatan layanan kesehatan kepada anak-anak yatim dhu'afa di berbagai tempat domisili mereka.Program ini memberikan layanan medis dasar yang meliputi kesehatan umum, gigi dan mata. Selain itu tim medis akan memberikan edukasi kesehatan bagi mereka. Layanan ini digulirkan minimal satu kali sebulan di setiap cabang-cabang yatim mandiri.

b. Klinik RSM 
Klinik RSM merupakan salah satu bentuk program kesehatan yatim mandiri untuk melayani masyarakat sekitar, utamanya anak yatim dhu'afa. Klinik ini memberikan layanan kesehatan keliling di beberapa cabang dan membuka jam praktek di klinik setempat.

c. GIZI

Selain memberikan layanan medis dasar, yatim mandiri juga memberikan suplemen tambahan guna meningkatkan gizi anakanak yatim dhu'afa pada saat layanan kesehatan dilakukan. Suplemen tambahan tersebut dapat berupa susu,roti,kacang ijo atau perlengkapan mandi.

d. SGQ

SGQ (Super Gizi Qurban) merupaka program optimalisasi qurban. SGQ adalah upaya mengelola qurban menjadi sosis dan cornet. Di harapkan dengan pengolahan daging qurban maka kemanfaatannya akan lebih lama dan lebih disukai anak-anak.

4. Program Pemberdayaan dan Ekonomi

BISA (Bunda Mandiri Sejahtera) adalah usaha dari yatim mandiri untuk mensejahterakan keluaraga anak yatim.Program ini berupa pembinaan keislaman, kepengasuhan dan pemberdayaan ekonomi. Dengan program ini diharapkan keluarga anak yatim menjadi lebih sejahtera dam mampu mandiri.

5. Program Ramadhan

Program ini merupakan program yang pasti digulirkan setiap tahunnya dibulan ramadhan oleh yatim mandiri untuk anak-anak yatim dhu'afa. Berbagai kegiatan telah dikemas mulai dari penyambutan bulan ramadhan sampai menjelang hari raya Idul Fitri. Penyelenggaraan program ini bersinergi dengan berbagai instansi untuk bersama-sama menyemarakkan bulan ramdhan. Berikut ini beberapa program yang diselenggarakan oleh yatim mandiri:

a. Buka puasa bersama

b. Bercahaya (Berbagi Ceria di Hari Raya)

c. Berbagi al-qur'an

d.Bina Lingkungan

6. Mandiri Entrepreneur Center

MEC adalah program diklat berbeasiswa bagi anak yatim lulusan SMA atau Sederajat.

7. Insan Cendekia Mandiri Boarding School

ICMBS adalah program pendidikan beasiswa untuk anak yatim tingkat SMP dan SMA. 
8. STAINIM (Sekolah Tinggi Agama Islam An Najah Indonesia Mandiri)

Program pendidikan S1 untuk anak yatim purna asuh. STAINIM memiliki tujuan menggali dan memperdalam serta mengembangkan keilmuan Islam (Ajaran Agama Islam) yang bersifat universal ke dalam berbagai disiplin ilmu secara konseptual, teoritis dan implementasinya demin meningkatkan kemampuan dan kualitas sumber daya manusia. (Wawancara dengan Bpk. Ahmad, 30 oktober 2018)

\section{Manajemen Fundraising Wakaf Uang pada Yatim Mandiri Kudus}

Secara garis besar Yatim Mandiri Kudus telah menjalankan fungsifungsi manajemen dengan baik. Berikut uraiannya:

\section{Perencanaan (Planning)}

Perencanaan merupakan fungsi yang paling mendasar dalam manajemen. Langkah awal sebagai penentu jalannya kegiatan dalam sebuah organisasi. Dalam menentukan perencanaan terdapat sebuah pertanyaan-pertanyaan pokok (basic question) yaitu what, why, where, when, who, and how disingkat $5 \mathrm{~W}+\mathrm{H}$ yang dapat membantu dalam membuat indikator perencanaan. Yatim Mandiri Kudus telah mengadopsi cara tersebut dalam manajemen fundraising wakaf uang.

Dalam awal perencanaan fundraising, ketua cabang benarbenar merencanakan fundraising dengan sangat baik. Sebagaimana yang telah dijelaskan dalam wawancara dengan kepala cabang Yatim Mandiri Kudus, Bapak Ahmad:

"Kalau perencanaan itu disusun dengan lebih matang, pertama yang mau kita tuju itu siapa dengan melakukan maping area (perkotaan, pedesaan), maping tujuan (instansi pemerintahan atau instansi swasta). Yang kedua penyampaian program kerja kita, dan yang keempat mempersiapkan SDM dan marketing tools."

Setelah melakukan perencanaan secara matang, selanjutnya Yatim Mandiri menentukan sasaran calon wakif yang akan dijadikan objek fundraising guna menggalang dana wakaf. Sebagaimana yang telah dijelaskan dalam wawancara dengan kepala cabang Yatim Mandiri Kudus, Bapak Ahmad:

"Kriteria sasaran donatur kita yaitu Muslim, instansi atau kantor (seperti instansi pemerintahan, sekolah, dan koperasi), 
walaupun mereka semua tidak punya keinginan ikut menjadi donatur di Yatim Mandiri tetapi minimal mereka tau bahwa kita sebagai pengelola ZISWAF yang amanah dan terpercaya."

Sedangkang dalam melakukan fundraising terdapat dua metode fundraising yang digunakan oleh Yatim Mandiri yaitu direct fundraising dan indirect fundraising. Metode direct fundraising yaitu fundraising yang dilakukan secara langsung ke lapangan. Tim ZISCo biasanya melakukan fundraising dilakukan sendirian, ada juga yang disebut canvansing yaitu fundraising yang dilakukan oleh beberapa orang 2-3 orang dengan mendatangi instansi pemerintahan ataupun non-pemerintahan. Sebagaimana yang telah dijelaskan dalam wawancara dengan kepala cabang Yatim Mandiri Kudus, Bapak Ahmad:

"Yang sering kita lakukan yaitu fundaising mandiri, itu biasanya kita agendakan di hari-hari efektif kerja. Trus ada juga canvasing, fundraising rame-rame cari donatur tapi rama-rame, jadi berkelompok 2-3 orang. Jadi datang kesuatu tempat menyampaikan ke calon donatur dengan memberikan majalah dan sebar brosur tapi beramai-ramai. Kami melakukan silaturahmi ke kantor-kantor swasta seperti koperasi, kantor perusahaan, instansi pemerintahan seperti sekolahan, kantorkantor pemerintahan, komunitas seperti pengajian, sholawat, komunitas penanganan aids dengan melakukan presentasi beberapa program dan memberikan majalah ataupun brosur di tempat tersebut. Sebelum presentasi biasanya kami mengirim surat pengantar terlebih dahulu".

Selain itu dalam metode metode indirect fundraising menggunakan media cetak, media online dan media elektronik seperti majalah, brosur, pemasangan banner, pemasangan iklan di radio, dan promosi di website serta sosial media (facebook dan instagram). Sebagaimana yang telah dijelaskan dalam wawancara dengan kepala cabang Yatim Mandiri Kudus, Bapak Ahmad:

"Untuk memperkenalkan kita dikhalayak luas d media sosial, Yatim Mandiri menggunakan media facebook, intagram, website, kalo website itu yang punya pusat. Kalo facebok sama instagram setiap cabang punya. Selain itu kita juga promosi program yang ada di Yatim Mandiri melalui radio. Disamping itu kita juga 
melakukan pemasangan banner di tempat-tempat strategis, biasanya kami melakukan ini menjelang bulan ramadhan".

Dalam metode yang digunakan Yatim Mandiri Kudus, peneliti mendapatakan sebuah informasi dilapangan bahwa dalam melakukan penghimpunan Yatim Mandiri Kudus cenderung aktif dalam metode direct fundraising. Sedangkan dalam metode indirect fundraising cenderung pasif dilakukan. Di era digital seperti ini seharusnya perlu dilakukan promosi penghimpunan secara aktif di media internet seperti media sosial dan website, sehingga bagi masyarakat yang sibuk dan sulit ditemui biasanya sering menggunakan media internet dalam mencari atau mendapatkan sebuah informasi. Diharapkan dengan aktif fundraising di media internet seperti advertorial dan image campaign dapat menggugah hati para netizen untuk mau berdonasi di Yatim Mandiri.

Tentunya dalam melakukan fundraising ada biaya transport yang sudah tercakup dalam biaya opersional lembaga. Biaya opersional yang diambilkan sekitar $10 \%$ dari total pengambilan ziswaf yang terkumpul menurut kebijakan dari kantor pusat. Dengan biaya operasional tersebut setiap cabangnya khususnya Yatim MandiriKudus harus pintar-pintar dalam memanajemen keuangan agar dapat mencapai pemenuhan kebutuhan secara maksimal.

\section{Pengorganisasian (Organizing)}

Pengorganisasian merupakan fungsi manajemen yang mengelompokkan orang dan memberikan tugas misi. Dengan adanya pengorganisasian, memungkinkan untuk sumber daya insani nazhir wakaf guna mencapai tujuan yang telah ditentukan dengan segala potensi yang ada secara efektif dan efisien. Pola perintah dan wewang di Yatim Mandiri dilaksanakan dengan pola strukturisasi top down, sehingga dalam ruang lingkup fundraising pemberian wewenang dan pengambilan keputusan dilaksanakan oleh Ketua Cabang.

Struktur lembaga Yatim mandiri cabang Kudus;

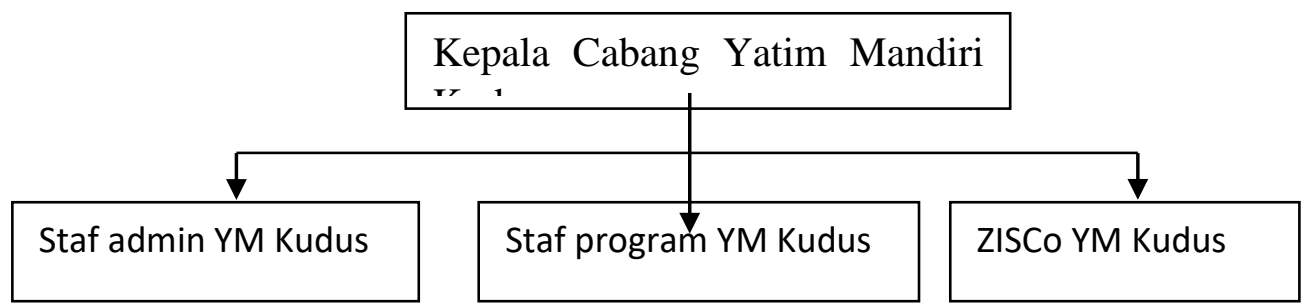

Dalam temuan penelitian yang dilakukan oleh peneliti, dilihat dari sturktur lembaga yang ada, tidak ada yang mengetuai dalam 
setiap staf atau divisi. Hal ini dirasa akan menambah beban operasional. Akan tetapi peneliti menyarankan agar dikasih ketua dalam staf ZISCo, hal ini akan menjadikan kinerja ZISCo lebih termanajemen dengan lebih baik karena ada yang memikirkan secara detail hal apa yang perlu dilakukan. Untuk memperoleh dana wakaf uang yang maksimal maka perlu tenaga fundraiser yang berkompeten dibidangnya dengan melalui perektrutan fundraiser. Dalam perekrutan seorang fundraiser, Yatim Mandiri memiliki kriteria tertentu yang dibutuhkan, Sebagaiamana yang dijelaskan oleh bapak Ahmad:

“Dalam perekrutan itu sendiri Yatim Mandiri memiliki kualifikasi tertentu untuk menjadi fundraiser yaitu pria dan wanita (Muslim), memiliki SIM C, memiliki sepeda motor, menyukai dunia lapangan dan sosial, serta niatnya bukan banya semata-mata bekerja saja tetapi juga dibarengi dengan ibadah".

\section{Pengarahan (Actuating)}

Pengarahan merupakan implementasi dari apa yang direncanakan dalam fungsi perencanaan dengan memanfaatkan persiapan yang sudah dilakukan dalam pengorganisasian. Pengarahan disebut efektif, jika dipersiapkan dan dikerjakan dengan baik serta benar oleh karyawan yang ditugasi.

Dalam temuan penelitian yang dilakukan oleh peneliti, dalam pengarahan kegiatan fundraising pada Yatim Mandiri dikoordinasi langsung oleh Kepala Cabang. Pembagian wilayah penghimpunan dana disebar menurut kemampuan dan wilayah terdekat dari fundraiser. Dalam pengarahannya Kepala Cabang memberikan bimbingan khususnya pada fundraiser baru dalam hal sebelum melakukan fundraising di masyarakat. Dalam bimbingan tersebut fundraiser baru diberikan pengenalan dasar seputar kantor Yatim Mandiri Kudus meliputi pengenalan kepada sejumlah pegawai yang ada, visi misi lembaga, kemudian memperdalam bimbingan dengan presentasi program-program yang ada di Yatim Mandiri guna menjadi bekal utama dalam penawaran kepada calon donatur untuk ikut serta membantu para yatim dhu'afa. Sebagaimana yang telah dijelaskan dalam wawancara dengan kepala cabang Yatim Mandiri Kudus, Bapak Ahmad:

"Pertama interview, seleksi, memperkenalkan diri ke Yatim Mandiri, pokoknya fokus pengenalan ke Yatim Mandiri dahulu 
kemudian memperdalam pengetahuan tentang Yatim Mandiri seperti mengetahui visi dan misi, program-program yang ada di Yatim Mandiri yang akan menjadi bekal utama dalam fundraising di masyarakat. Setelah itu fundraiser baru saya dampingi selama satu bulan dalam fundraising agar tau bagaimana langkah dan sikap yang harus dilakukan. Lihat, amati dan tiru. Setelah satu bulan pendampingan maka sudah dianggap bisa fundraising mandiri di bulan berikutnya."

Selain itu juga diajarkan bagaimana cara berkomunikasi dan bersikap yang baik serta diajarkan juga untuk menerima penolakan dari calon donatur. Fundraiser juga dibekali pemahaman secara mendalam tentang ayat-ayat Al-Qur'an, Hadits, fadhilah ziswaf agar calon donatur semakin yakin untuk menjadi donatur di Yatim Mandiri Kudus.

Kepemimpinan seorang kepala lembaga sungguh sangat mempengaruhi, khususnya pada Yatim Mandiri cabang Kudus. Karena bisa dilihat dari strukturnya kepala cabang langsung mengomando semua kegiatan.Hal ini perlu hubungan yang baik kepada seluruh staf, komunikasi yang baik dalam setiap pengarahannya yang sudah tertera dalam fungsi manajemen. Dengan menjalin komunikasi yang baik akan mengurangi miskomunikasi antar anggota sehingga dalam penyampaian mulai dari pemberian bimbingan dan pelatihan, pemberian pemahaman program dan seputar tentang ziswaf hingga pelaksanaan fundraising di masyarakat akan berjalan sesuai perencanaan.

\section{Pengawasan (Controlling)}

Pengawasan adalah aktivitas untuk meyakinkan bahwa semua hal berjalan seharusnya dan memonitor kinerja lembaga.Untuk melakukan pengawasan dalam suatu lembaga yng efektif dan efisien harus mengetahui kunci-kunci pengawasan. Sebagaimana temuan peneliatian yang dilakukan peneliti sebagai berikut;

Pertama, pengendalian berawal dari diri sendiri dengan keyakinan apa pun yang dilakukan akan diawasi oleh Allah swt. Kedua, pengawasan berjalan dengan baik apabila pemimpinnya memang orang-orang yang pantas untuk menjadi pengawas dan pengontrol. Ketiga, membangun sistem lembaga dengan baik.Pengawasan kinerja di kantor cabang diawasi oleh Ketua Cabang sendangkan Ketua Cabang bertanggungjawab terhadap kinerja kantornya di kantor pusat (Surabaya). Khususnya dalam kinerja 
fundraiser setiap minggunya dilakukan evaluasi kinerja. Didalam evaluasi kinerja tersebut terdapat pengoreksian terdahap target pengambilan fundraiser, konsultasi kendala yang dihadapi dan melaporkan melakukan kunjungan baru atau melaporkan adanya donatur baru. Untuk memberi semangat dalam fundraising, Yatim Mandiri akan memberikan penghargaan berupa umroh jika ZISCo dapat melebihi target pengambilan rutin, pengambilan target dan perolehan global yang akan di pilih ZISCo terbaik dari yang terbaik oleh kantor pusat. Akan tetapi jika pekembangan ZISCo setiap bulannya tidak baik maka akan diberikan surat peringatan kerja atau bahkan bisa diberhentikan kerja. Sebagaimana yang telah dijelaskan dalam wawancara dengan kepala cabang Yatim Mandiri Kudus, Bapak Ahmad:

"Untuk melihat kinerja dari fundraiser, kantor kita sudah dilengkapi dengan alat absensi otomatis atau yang absensi check clock. Jadi terlihat secara otomatis kedatangan fundraiser di kantor. Kantor kita beroperasi dari hari senin sampai dengan sabtu mulai dari pukul 08:00 - 16:00 WIB. Dalam pengukuran prestasi ada sifatnya cabang dan nasional atau pusat. Kalo pusat, yang disampaikan ke Zisco pertama, kalo dia mencapai sesuai target ya otomatis dia dapat bonus yang sudah masuk rumus keuangan, artinya bonusnya insha Allah lebih tinggi dari yang lain. Terus yang kedua kalo dia, sering kan kita ada 12 bulan kalo dia semakin sering banyak mencapai target dan bagus nah nanti ada reward khusus kalo memang dia yang terbaik dari yang terbaik maka bonus yang paling besar adalah umroh, jadi semuanya ya pengambilan rutin, pengambilan target, perolehan global. Jadi nanti Zisco terbaik dicabang diajukan ke nasional kan ada 42 cabang lha itu disaring lagi untuk menjadi terbaik dari yang terbaik dan bisa mendapatkan umroh. Kalau tidak mencapai target ya diingatkan, diingatkan itu kan dengan lisan dulu secara halus, kalau yang kedua masih tetap saja tidak ada perkembangan diingatkan lagi dengan lisan tapi dengan nada dan tekanan yang berbeda, efeknya kalo tidak memiliki perkembangan nanti akan menjadi keirian bagi temen-temen ZISCo yang lain, dan tindakan terakhir kalaupun tetap begitu akan diberikan surat keputusan untuk berhenti bekerja."

Controlling dalam Yatim Mandiri cabang Kudus sudah berjalan dengan cukup baik dan sesuai dengan standar langkah-langkah 
dalam fungsi manajemen. Mulai dari penetapan standar dan metode yang digunakan untuk mengukur prestasi, mengukur prestasi kerja, menganalisis apakah kerja memenuhi syarat dan mengambil tindakan korektif.

Dengan adanya pengawasan dalam manajemen fundraising wakaf uang khususnya kinerja fundraiser hal ini akan menjamin berjalannya pekerjaan sesuai dengan perencanan, kebijakan dan prosedur yang sudah ditetapkan lembaga serta menghindari terjadinya penyalahgunaan dan pemborosan anggaran. ${ }^{15}$

\section{Kesimpulan}

Berdasarkan uraian yang ada pada pembahasan mengenai manjemen fundraising wakaf di Lembaga Yatim Mandiri Kudus, dapat disimpulkan bahwa, Perencanaan Yatim Mandiri Kudus melakukan secara baik, dengan membuat susunan program yang akan disampaikan, dan dengan menerapkan dua metode fundraising yaitu direct dan indirect Fundraising. Pengorganisasian dan pengarahan sudah dilaksanakan dengan baik, penentuan wilayah pengambilan, perekrutan dan pembimbingan fundraiser baru yang dipimpin langsung oleh ketua cabang Yatim Mandiri Kudus. Dan juga pengawasan yang termanejemen dengan baik pula, mulai dari pengukuran kinerja pegawai fundraiser dan prestasinya.

\section{Daftar Pustaka}

Ali, Khalifah Muhammad; Meida Yudiani; Sri Mulatsih (2018), “ApekAspek Prioritas Manajemen Wakaf di Indonesia", al-Falah: Journal of Islamic Economics, 3(1).

Ali, Khalifah Muhammad; Meida Yudiani; Sri Mulatsih (2018), "ApekAspek Prioritas Manajemen Wakaf di Indonesia", al-Falah: Journal of Islamic Economics, 3(1).

Anaroga, Pandji. Manajemen Bisnis. Jakarta: Rineka Cipta, 2014.

Bungin, Burhan. Penelitian Kualitatif. Jakarta: Kencana, 2008.

Dwijokangko, Ayup. (2018), “Manajemen Fundraising Wakaf Uang pada Yatim Mandiri", Skripsi, IAIN Tulungagung.

Harahap, M. Guffar (2019), "Strategi Fundrasing Wakaf di Badaan Wakaf Pondok Pesantren Mawaridussalam", AT-Tawassuth, IV(2).

${ }^{15}$ Wawancara dengan Bpk. Ahmad, 30 oktober 2018 
Huda, Miftahul. (2015), "Model Manajemen Fundraising Wakaf", Jurnal alAhkam, 13(1).

Kalida, Muhsin. (2004), “Fundraising dalam Studi Pengembangan Lembaga Kemasyarakatan, Jurnal Aplikasia, V(2).

Qahaf, Mundzir. Manajemen Wakaf Produktif. Jakarta: Khalifa, 2005.

Rozalinda, Manajemen Wakaf Produktif. Jakarta: Rajawali Press, 2016.

Septiyani, Rahmi; Ahmad Djalaluddin; Misbahul Munir (2018), “Telaah Strategi Fundraising Wakaf Tunai Mewujudkan Pemberdayaan Masyarakat (Studi kasus Kawasan Baitul Maal Hidayatullah Perwakilan Jawa Timur)", Islamic Economics Quotient, 1(2).

Sugiono, Memahami Penelitian Kualitatif. Bandung: Alfabeta, 2012.

Suhendi, Hendi (2018), “Optimalisasi Aset Wakaf sebagai Sumber Dana Pesantren Melalui Pelembagaan Wakaf", Tahkim, Jurnal Peradaban dan Hukum Islam, 1(1).

Suhrawandi, K. Lubis. Wakaf dan Pemberdayaan Umat. Jakarta: Sinar Grafika, 2010.

Wawancara, (Ahmad, 30 oktober 2018) 